\title{
The implementation of Pre-Lecture Resources to Reduce In-Class Cognitive Load: A Case Study for Higher Education Chemistry
}

\author{
Michael Seery \\ Technological University Dublin, michael.seery@tudublin.ie \\ Roisin Donnelly \\ Technological University Dublin, roisin.donnelly@tudublin.ie
}

Follow this and additional works at: https://arrow.tudublin.ie/scschcpsart

Part of the Science and Mathematics Education Commons

\section{Recommended Citation}

Seery, M. K. and Donnelly, R. (2011), The implementation of pre-lecture resources to reduce in-class cognitive load: A case study for higher education chemistry. British Journal of Educational Technology. doi: 10.1111/j.1467-8535.2011.01237.x doi.org/10.21427/t658-wv37

This Article is brought to you for free and open access by the School of Chemical and Pharmaceutical Sciences at ARROW@TU Dublin. It has been accepted for inclusion in Articles by an authorized administrator of ARROW@TU Dublin. For more information, please contact arrow.admin@tudublin.ie, aisling.coyne@tudublin.ie, gerard.connolly@tudublin.ie.

Funder: Higher Education Authority Strategic Innovation fund

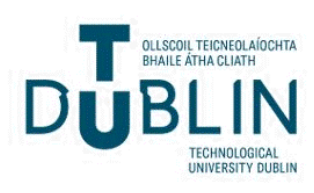


The implementation of pre-lecture resources to reduce in-class cognitive load: A case study for higher education chemistry

Michael K. Seery and Roisin Donnelly

Michael Seery is a Lecturer in Chemistry researching chemical education and Roisin Donnelly is a Learning Development Officer at the Learning Teaching and Technology Centre, both at the Dublin Institute of Technology. Address for Correspondence: Michael Seery, School of Chemical and Pharmaceutical Sciences, Dublin Institute of Technology, Kevin St., Dublin 8, Ireland. Email: michael.seery@dit.ie

\begin{abstract}
This case study describes an effective method to ameliorate the cognitive load caused by new terminology and concepts in lectures. Ten online pre-lecture resources whose design was underpinned by the principles of cognitive load theory were provided to a class of 49 first year university level chemistry students. Each resource introduced a number of key concepts to the forthcoming lecture and included a quiz for students to test understandings and identify misconceptions. The evaluation of the implementation of resources was measured by considering the difference in exam marks for in-semester test and end of module exam. These showed that the marks for students who had no prior knowledge of chemistry before coming to college significantly improved to the point that there was no difference between students with and without prior knowledge. A key outcome of this work is that providing students with resources to prepare for lectures can help in reducing their cognitive load.
\end{abstract}

\title{
What is already known about this topic
}

- Prior knowledge (e.g. from school level) is a strong predictor factor for future performance (e.g. at college level).

- Cognitive load theory describes how the working memory has a limited capacity to process new information.

- E-resources can be designed so as to minimise the difficulty of extracting new information from the resources.

\section{What this paper adds}

- Designing e-resources to introduce some core concepts for a lecture can help students identify these in a lecture with a lot of new terminology.

- These e-resources can be easily embedded into the virtual learning environment so that students can access resources, complete quiz and receive feedback and a grade with little extra work for the lecturer.

- These e-resources can provide a basis for in-lecture discussion between students and between lecturer and students to further discuss content using core terminology.

\section{Implications for practice/policy}


- Embedding of the resources into the module design is important to attribute them value. The lecture should build on the material introduced in the e-resource.

- Feedback should be as rich as possible, correcting wrong ideas for novices to the discipline and misconceptions for those with prior knowledge.

- Identifying core concepts in a structured way before each lecture, and providing feedback on students' understanding of these, give students an opportunity to take control of their own learning both before and after a lecture.

\section{Introduction}

Over ten years ago, Norman Reid produced evidence to show pre-lecture resources designed to reduce the cognitive load of novice learners in chemistry had the effect of removing the existing correlation between qualification in chemistry at school level and performance in end of year exams in the first year at university (Sirhan, Gray, Johnstone, \& Reid, 1999). The resources were specifically designed to reduce the cognitive load of learners in the lecture hour by introducing them to key terms prior to the lecture (Sirhan \& Reid, 2001). This work seeks to incorporate Reid's idea into a model whereby the pre-lecture activity can be delivered and administered through a virtual learning environment rather than requiring additional in-class tutors.

The assimilation of new knowledge by novice learners is strongly influenced by their prior knowledge of a topic - how well the new information can be linked to existing knowledge in the long term memory (Dochy, Segers, \& Buehl, 1999). The reason is attributed to the fact that learners without prior knowledge must use a significant proportion of the limited working memory capacity in accommodating new terminology and concepts, whereas learners with prior knowledge can progress to linking new information with existing knowledge. These concepts from cognitive load theory were confirmed in a research project in our institution, which demonstrated there was a significant difference in the examination achievement of chemistry students who had and those who had not some prior knowledge of chemistry (Seery, 2009). This is an observation that has been demonstrated in numerous other studies across several disciplines (Dochy, et al., 1999).

The development of electronic resources incorporating the principles of cognitive load theory may be a strategy to reduce the burden on the working memory of novice learners in a variety of subject disciplines. Collard and co-workers used this effectively in chemistry in a process aimed at encouraging students to engage with the text book prior to the lecture, with students reporting that the resources helped them understand in-lecture material better (Collard, Girardot, \& Deutsch, 2002). Similar pre-lecture work involving text books was completed in the teaching of psychology students (Lineweaver, 2010). The use of pre-lecture quizzes to identify areas of difficulty to address during the lecture was described for chemistry (Slunt \& Giancarlo, 2004) and psychology (Narloch, Garbin, \& Turnage, 2006). Recent work on the use of credit-awarding pre-lecture learning resources has been described for physics, (Chen, 
Stelzer, \& Gladding, 2010) with the explicit intention of reducing the in-lecture cognitive load.

Design considerations for multimedia learning materials in the context of cognitive load theory have been described by various researchers (Ayres \& Paas, 2009; Clarke \& Mayer, 2008; Mayer, 2005; Sweller, 2008). Three types of cognitive load are identified: intrinsic, extrinsic and germane load. Intrinsic load is caused by the unfamiliarity and/or complexity of the material. This depends on the level of expertise of the learner - the extent of their prior knowledge. Extraneous load depends on the quality or nature of the instructional materials. Poor materials or those that require a large amount of working memory to process will increase the load and leave little capacity for learning. Germane load is the mental effort required for learning. Due to the limited capacity of the working memory, germane load (the extent of learning) is dependent on the extent of the extraneous load, and also on the material and expertise of the learner - the intrinsic load. An expert on a topic is able to draw from prior knowledge, and release working memory capacity for germane load processing. Cognitive load theory informs the design of e-resources (Clarke \& Mayer, 2008). Briefly, information should be presented as complementing visual and audio so as to maximise the use of how the learner can perceive the information ("modality principle"), with mutually dependent information presented coincidentally ("contiguity principle").

In this case study, the design of pre-lecture resources for an introductory chemistry module from the perspective of cognitive load theory is considered. The paper aims to draw key elements from previous studies detailed above into online electronic resources which will both reduce cognitive load and facilitate in-class work, and incorporate a quiz for students to check their understanding. Factors around the implementation of the resources to a group of learners with mixed levels of expertise are surveyed, and an analysis of the impact of the resources on those with and without prior knowledge is examined through a quantitative analysis of examination marks. Lessons drawn from the experience are collated with a view to providing a guide to other practitioners interested in adopting this approach in their own teaching.

\section{Methodology and Methods}

Methodology: The case study design was chosen as it suited the conditions of this research project very well, allowing naturalistic methods of enquiry such as researcher reflections to be carried out, side-by-side with quantitative data gathering. The flexibility of the case study approach allows the design to "emerge" (Robson, 2002) during data collection and analysis. The three main reasons for using case study as a methodology in this project was so that it could lead to a greater understanding of the context of the evaluation of the pre-lecture resources, it allowed the researcher to collect information on outcomes not known prior to the initiative, and finally it portrayed the multiplicity of causes that are associated with various outcomes in the project.

Design and delivery of resources: The model for the resources developed for this study aimed to prepare materials for students so that they would be introduced to terminology required for 
a lecture. This was complemented with a short quiz including answer-specific feedback so that students could check their own understanding and address common misconceptions. The resources took no longer than five minutes to complete, excluding time required for the quiz. The design of the resources was kept sparse with just the key information clearly accessible, with the explicit intention of reducing extrinsic cognitive load. Each resource had a small amount of text on screen, with the bulk of the information presented as audio, presented coincident with the on-screen information, so as to align with the modality and contiguity principles derived from cognitive load theory (Clarke \& Mayer, 2008). The resources were produced using Articulate ${ }^{\circledR}$ Studio '09, and took approximately one hour to develop per resource, once the interaction template had been generated. The work at this stage mainly relied on subject-matter expertise - what terms to include in the resource and what questions to use in the resource quiz which would best address the misconceptions for each issue. The quizzes used in the resources were SCORM enabled (version 1.2) which allows access duration and quiz score to be collected. The resources were embedded in Blackboard Learning System - CE Enterprise License (Release CE 8.0.1) and were available for 10 onehour lectures, which were held twice weekly on Mondays and Thursdays in the first half of a twelve-week semester. Resources for each lecture were made available immediately after the preceding lecture.

Quantitative Data Analysis: The pre-lecture resources were delivered to a group of students ( $\mathrm{N}=49,28$ male, 21 female) undertaking an introductory module in chemistry in a large tertiary institution in Dublin, Ireland. Information on students' academic background was collected from the Admissions Office of the institution, and coded as described elsewhere (Seery, 2009) to give a prior knowledge score for chemistry at school level ('PK', range 0 100) and the overall performance at school level (the Central Applications Office points score, 'CAO', range 0 - 600). The CAO score is used by colleges to set minimum entrance requirements each year based on the popularity of the courses. Marks obtained in a semester test held mid-way through the module ('SEM') and an end of module exam ('EXAM') were also recorded. Statistical analysis was carried out using SPSS version 18.0 for Windows. Twenty-five students out of the sample of 49 had completed chemistry in their final exam at school level (the Leaving Certificate). There was no difference between the average CAO mark or the average maths mark when comparing groups who had completed chemistry than those that hadn't $(p<.05)$.

Reflections on Implementation: Throughout the development and implementation, a research diary was kept of any issues that arose and points of note. In addition, a colleague of the author reviewed some of the online resources in the context of the discipline and provided critical feedback on these. Resulting changes in teaching practice from the previous years of teaching the module arising out of the introduction of the resources were also logged.

\section{Results and Discussion}

Cognitive considerations in design of resources 
Ten pre-lecture resources were developed to address lectures on introductory topics in chemistry. From the perspective of cognitive load theory, the resources aimed to introduce a small number of terms prior to each lecture to reduce the intrinsic cognitive load. The first step was to consider the lecture content and the desired outcomes from each lecture. Following this, any terminology that would be new or unfamiliar to a novice learner was listed. The most significant of these were identified and flagged to be included in the prelecture resource. As an example, the first lecture in an introductory chemistry module usually looks at the structure of the atom, and explains how this structure was arrived at. The most significant outcome of this lecture was thus decided to be "to describe the structure of the atom and how this leads to the definition of an element". There were at least eighteen unfamiliar terms in the first lecture: atom, electron, proton, neutron, nucleus, alpha-particles, radioactivity, element, atomic number, mass number, isotopes, deuterium, tritium, density, atomic mass unit, mass spectroscopy, ionised. In the pre-lecture resource the most fundamental of these: atom, electron, proton, neutron, nucleus and isotope were introduced. In addition, the word nucleus has different meanings in chemistry and biology, which students would be studying concurrently, so this was highlighted. de Jong describes these as different ontological categories, which can increase the learning difficulty of new materials (de Jong, 2010).

In order to minimise the extrinsic load, the resources were generally devoid of context and interesting anecdotes that would usually be incorporated in a lecture, which from the perspective of cognitive load theory, these are redundant information in this context. A concern with this approach was that they would be very dull. Audio accompanying the resource was intentionally kept quite casual, and the resources themselves were not long usually three to five minutes. This is significantly shorter than those developed in a similar strategy for physics at Illinois (Chen, et al., 2010), who aimed to cover most of the material that would be presented in a lecture. The design principle behind the resources in this study was to prepare students for their learning in the lecture rather than summarise the lecture content. In the Illinois case, the lecture format also changed, as much of the material had been presented in the pre-lecture (Stelzer, Brookes, Gladding, \& Mestre, 2010). In this case, the lecture built on the pre-lecture introduction and/or tasks required in the pre-lecture (for example students being asked to review some concept).

The resource was a Flash object, with several methods for navigation, and tabs to indicate which section is currently active (Figure 1). Bearing in mind the modality of information, written text was kept to a minimum - usually to annotate diagrams or provide definitions and most explanations were by audio. Audio and interactions were simultaneous to reduce split attention. Subtitles were available, but were turned off by default.

\section{$>>$ INSERT FIGURE 1}

\section{Resource Quiz}

Each pre-lecture resource had a quiz associated with it, with four questions. The quiz had several purposes. Questions were structured so that common mistakes or misunderstandings 
were included, and answer specific feedback meant that students could reinforce their understanding of content and increase confidence - an important consideration for first years unsure of how they are doing in a new system. It was worth considering carefully the design and requirements of the quiz - they were to provide some feedback on some key concepts prior to the lecture rather than assess the expected knowledge after the lecture. Some initial quizzes were redesigned following discussion with a colleague to ensure that they better aligned with this principle. The quiz was SCORM-enabled, and the mark obtained was reported to the virtual learning environment (VLE) gradebook immediately after the period of availability of the resource. Based on student queries in classroom regarding quiz and concerns over the release of their score, it appeared that students were in general keen to complete the quiz and ensure their marks were recorded, even though the assessment was worth only a small component of their module mark (1.5\%).

\section{Analysis of usage of resources}

The students were delivered two lectures a week by the module instructor; one on Monday afternoon and one on Thursday morning. The resource for each lecture was scheduled to be available immediately after the preceding lecture until just before the lecture, giving students four days to view the resource for Monday lectures and three days to view the resource for Thursday lectures. At the request of students, the resources were left available after the allocated time, but analysis of access data is restricted to the time ranges described above.

After introducing the resource, the proportion of students who accessed and completed the resource was typically over $80 \%$, although there was a low level of access in the first weekend (Resource \#2 - 33\%). However, the system quickly stabilised with students engaging with the resource. There was no evidence to show that students that had prior knowledge accessed the resources more or less than those that had not - usage was uniform across the group.

\section{$>>$ INSERT TABLE 1}

Analysis of the access data (Table 1) demonstrates that most students typically accessed the resources on either Sunday afternoons for the Monday lecture or Wednesday evenings for the Thursday lecture. The predominant reason for accessing the module on the VLE was to access the resources - the proportion of time spent in the module on the resource (represented by the \% total time on SCORM) was on average $73 \%$. This does not include a "blank" session, where a tutorial was held instead of a lecture. During this time, students still accessed the module, but for access to other learning materials or the gradebook - only 12 out of 81 module accesses were to view (previous) resources.

The average time spent on each SCORM resource is given in Table 2, but to obtain a richer account on access times, the time spent by each student on each resource was recorded and reported in the SCORM report. Figure 2 shows the frequency distribution spent on each resource and the proportions in each time range for all resources.

\section{>>INSERT FIGURE 2}


The time bands shown in Figure 2 are two minutes (incorporating any use of the resource for up to two minutes), five minutes (incorporating the use of the resource for more than two minutes but not more than five minutes), ten, fifteen, twenty, forty and sixty minutes. The resources take three - five minutes to watch plus whatever additional time is required to complete the quiz. Therefore the two minute section captures any student who clicked on the resource and did not complete it, or clicked on the resource, immediately accessed quiz and completed it within one minute - in other words those who did not interact with the resource itself. This proportion is quite low, on average about $14 \%$ - a figure which would also include students for whom the material was not new, and who were able to proceed to the quiz. The access data between two and twenty minutes, shaded by various light grey colours in the stack plot in Figure 1, represents students who would have engaged with the resource and considered the quiz. As can be seen from the plot, this range is representative of the majority of the sample; about $65 \%$ of students. This is in line with the findings by Stelzer in his work, who typically recorded $60-70 \%$ as "viewers" of their pre-lecture resources - students who spent more than $75 \%$ of the audio narration time on the resource (Chen, et al., 2010).

Students in this time range would have adequate time to watch resource, and attempt quiz while consulting the resource and/or other materials. Students in the higher time regions, above twenty minutes, may either have had great difficulty with the quiz or simply opened the resource and left it, until it timed out after one hour. However the latter reason is unlikely, as $97 \%$ of students had completed the resource after 40 minutes.

The performance in the quiz of the resource was examined. The quiz structure was the same in each resource - four questions with equal marks. Question types were generally of the multiple choice or matching-pairs type. Alternate answers were sourced from common misconceptions observed in previous tests administered to this class group in previous years, as well as those identified in the literature on chemical misconceptions (Chandrasegaran, Treagust, \& Mocerino, 2007). The quiz was purposefully made very easy, as the goal here was to reinforce, with feedback when required, key terms and concepts prior to the lecture rather than assess knowledge that would be expected as a result of the lecture, as well as provide confidence and motivation to students coming into the lecture. Therefore their purpose was diagnostic or formative rather than summative. Performance on the quiz was generally very good (typically $>75 \%$ ) once students had engaged with the resource. Answer specific feedback helped students diagnose their own misconceptions. Given the nature and design of the quiz, it was not surprising that there was no correlation between quiz mark and prior knowledge of chemistry.

\section{Analysis of performance in semester test}

Mid-way through the semester, students undertake a test on the material in lectures $1-7$. A test of similar structure has been given to students on this module for the past six years (Seery, 2009). In each of these, students with prior knowledge of chemistry (average test mark of 63\%) have out-performed those who have no prior knowledge (average test mark of $44 \%$ ) - a gap of $19 \%$ (Seery, 2009), with the average mark between the two groups being significantly different $(t=5.2, d F=71, p<.0005)$. Analysis of the marks in the current study show the average mark for students who have prior knowledge was $61 \%$, while that for those 
with no prior knowledge of chemistry was $55 \%$ - a narrowing of the gap to $6 \%$. Furthermore, there was no significant difference between these two averages $(p<.05)$. The data for the current year (Year 1 on the $\mathrm{x}$-axis) along with several previous years is shown in the boxplots in Figure 3. These show the range of marks from lowest to highest, the average mark (solid horizontal line) and the four interquartile ranges.

\section{>>INSERT FIGURE 3}

\section{Analysis of performance in end of module exam}

At the end of semester 1, students take a module examination, and as with the semester test, annual analysis over the past several years has demonstrated that there is a strong, significant correlation between prior knowledge and performance in the end of year exam (Seery, 2009). Analysis of students' marks in this study showed that the difference between the average mark between those with and without prior knowledge had disappeared, with no significant difference between the averages $(t=0.61, d F=41, p<.05)$.

\section{Correlational analysis}

In the previous study, prior knowledge was the sole, highly significant factor predicting the semester and module exam marks. In contrast, in a correlational analysis of the current data, prior knowledge does not significantly correlate with either the semester or module exam mark (Table 2). The semester and exam marks strongly correlate with each other $(p<0.01)$, as does CAO mark with the module exam mark. This data indicates that prior knowledge is not a factor in the success or otherwise in the module exam, and is a significant outcome from this study, given that prior knowledge is a universal indicator of future performance (Dochy, et al., 1999). This result, while brought about by the implementation of pre-lecture resources, should also be considered in light of the impact the introduction of the pre-lecture resources had on the lecturer.

\section{$>>I N S E R T$ TABLE 2}

\section{Impact on teaching practice}

While the model described here for introduction of pre-lecture resources does not directly impose any changes on the structure of the lecture, some intended and unintended consequences were recorded. In the lecture the online resource was purposefully integrated, ranging from incidental references (such as saying "as mentioned in the pre-lecture") to building on work initiated in the pre-lecture. For example, students were occasionally asked to review some experiment or concept in their own time before the lecture, with some ideas seeded in the pre-lecture resource. In the lecture, time would then be devoted to allow students to discuss in small groups their findings, and then as a class would build up the notes on that concept, guided by the lecturer. This differed with the previous situation where students were simply being lectured about a particular concept while filling in skeleton notes, and resulted in a noisier, but more engaged classroom, and reflecting Reid's original model where students worked in small groups to discuss key terms with their lecture (Sirhan, et al., 1999). Therefore the pre-lecture resources enabled a much greater level of discussion in the 
lectures, which in turn left students able to check their understanding of particular topics, either while talking to each other or reporting back to the class. Similar findings that lecture preparation had led to more in-lecture discussion was reported in a study structuring students' use of textbooks prior to lectures (Collard, et al., 2002)

The high level of engagement with the resources were initially surprising, as it was expected that the resources' small assessment mark (1.5\% of module mark) would have to be used as an incentive to encourage students to use the resources. However, this was not mentioned until mid-way through the implementation of the resources. Students did receive feedback on completion of each question in the resource and their mark was provided automatically after each lecture - and it is proposed that this was a driver for engagement. This is evidenced by a high level of access during the "blank" period, when no resource was available - the most accessed time was immediately after the marks were made available for the preceding resource (Thursday $1-2$ pm just after the $12-1$ lecture). Furthermore, an advantage of implementing these resources with first year students is that they are open to new processes as they are less aware of what is expected of them at university level. Much of the work on the first year experience has identified that students in the early stages of year 1 are unclear of what is expected of them because of a reduction in the level of feedback compared to what they are used to at school level (Yorke \& Longden, 2004). They continue that students should have a sense of agency in their own learning. Nicol, in his work on e-assessment with year 1 students, has demonstrated through several case studies how the use of online formative assessment can encourage this sense of agency or self-regulation (Nicol, 2007, 2009). It is intended as a consequence of this study to further examine students' engagement and experiences of these resources.

The process of implementing these resources led to some changes in teaching style. Reviewing the amount of new terminology for each lecture prompted significant reflection on how many terms students were exposed to in introductory chemistry lectures, reflecting a larger debate currently being discussed by chemistry educators (Cooper, 2010; Johnstone, 2009). Therefore much more care was taken in introducing new terms, both in terms of spending time explaining terms and how they related with other previously introduced concepts and care over terms that might have different meanings in different contexts.

\section{Summary}

The introduction of pre-lecture resources to year 1 students undertaking a standard university level introductory module was implemented. Access to the resources was high among the group of students. The resources presented some key information relevant for introducing a lecture and allowed for answer-specific feedback and a mark to be given to students on completing a quiz. On implementing the resources, it was found that the difference in achievement between students that had and students that did not have prior knowledge of chemistry in their semester test and end of module exam marks had diminished to the point where there was no significant difference between each group - a considerable difference to the situation that existed in previous years. As well as discussion of the implementation and usage of resources themselves, some additional factors relating to the implementation and the 
consequences to the lecture style and student engagement in year 1 are outlined. The use of online pre-lecture resources is considered to be an effective intervention worthy of consideration by practitioners from a diverse range of technical disciplines, who are interested in cultivating their students' learning capacity.

\section{Acknowledgements}

The authors wish to thank Dr. Claire Mc Donnell for her input into the development of this project. MS wishes to thank the Higher Education Authority Strategic Innovation fund for a Teaching Fellowship.

\section{References}

Ayres, P. , \& Paas, F. (2009). Interdisciplinary Perspectives Inspiring a New Generation of Cognitive Load Research. Educational Psychology Review, 21(1), 1-9.

Chandrasegaran, A. L., Treagust, D. F., \& Mocerino, M. (2007). The development of a two-tier multiple-choice diagnostic instrument for evaluating secondary school students' ability to describe and explain chemical reactions using multiple levels of representation. Chemistry Education Research and Practice, 8(3), 293 - 307.

Chen, Z., Stelzer, T., \& Gladding, G. (2010). Using multimedia modules to better prepare students for introductory physics lecture. Physical Review Special Topics - Physics Education Research, 6(010108), 1 - 5.

Clarke, R. C., \& Mayer, R. E. (2008). E-Learning and the science of instruction (2nd ed.). San Francisco: Pfeiffer (Wiley).

Collard, D. M., Girardot, S. P. , \& Deutsch, H. M. (2002). From the Textbook to the Lecture: Improving Prelecture Preparation in Organic Chemistry. Journal of Chemical Education, 79(4), 520 - 523.

Cooper, M. (2010). The Case for Reform of the Undergraduate General Chemistry Curriculum. Journal of Chemical Education, 87(3), 231-232.

de Jong, T. (2010). Cognitive load theory, educational research, and instructional design: some food for thought. Instructional Science, 38(2), 105-134.

Dochy, F. J. R. C., Segers, M., \& Buehl, M. M. (1999). The relation between assessment practices and outcomes of studies: The case of research on prior knowledge. Review of Educational Research, 69, 145-186.

Johnstone, A. H. (2009). You Can't Get There from Here. Journal of Chemical Education, 87(1), 22-29.

Lineweaver, T. T. (2010). Online Discussion Assignments Improve Students' Class Preparation. Teaching of Psychology, 37(3), 204 - 209.

Mayer, R. E. (2005). Cognitive theory of multimedia learning. In R. E. Mayer (Ed.), Cambridge handbook of multimedia learning (pp. $31-48$ ). Cambridge: Cambridge University Press.

Narloch, R., Garbin, C. P., \& Turnage, K. D. (2006). Benefits of Prelecture Quizzes. Teaching of Psychology, 33(2), $109-112$.

Nicol, D. (2007). Laying a foundation for lifelong learning: Case studies of eassessment in large 1st-year classes. (Article). British Journal of Educational Technology, 38(4), 668-678. 
Nicol, D. (2009). Assessment for learner self-regulation: enhancing achievement in the first year using learning technologies. (Proceedings Paper). Assessment \& Evaluation in Higher Education, 34(3), 335-352.

Robson, C. (2002). Real World Research (2nd ed.). Oxford: Blackwell Publishing.

Seery, M. K. (2009). The Role of Prior Knowledge in Undergraduate Performance in Chemistry - A Correlation-Prediction Study. Chemistry Education Research and Practice, 10, 227-232.

Sirhan, G., Gray, C., Johnstone, A. H., \& Reid, N. (1999). Preparing the Mind of the Learner. University Chemistry Education, 3(2), 43-46.

Sirhan, G. , \& Reid, N. (2001). Preparing the mind of the learner - part 2. University Chemistry Education, 5, 52 - 58.

Slunt, K. M. \& Giancarlo, L. C. (2004). Student-Centered Learning: A Comparison of Two Different Methods of Instruction. Journal of Chemical Education, 81(7), 985 - 988.

Stelzer, T., Brookes, D. T., Gladding, G., \& Mestre, J. P. (2010). Impact of multimedia learning modules on an introductory course on electricity and magnetism. American Journal of Physics, 78(7), 755 - 759.

Sweller, J. (2008). Human Cognitive Architechture. In J. M. Spector, M. D. Merrill, J. van Merrienboer \& M. P. Driscoll (Eds.), Handbook of research on educational communications and technology (3rd ed., pp. 369-381). New York: Routledge.

Yorke, M., \& Longden, B. (2004). Retention and student success in higher education. Maidenhead: Society for Research into Higher Education: Open University Press. 


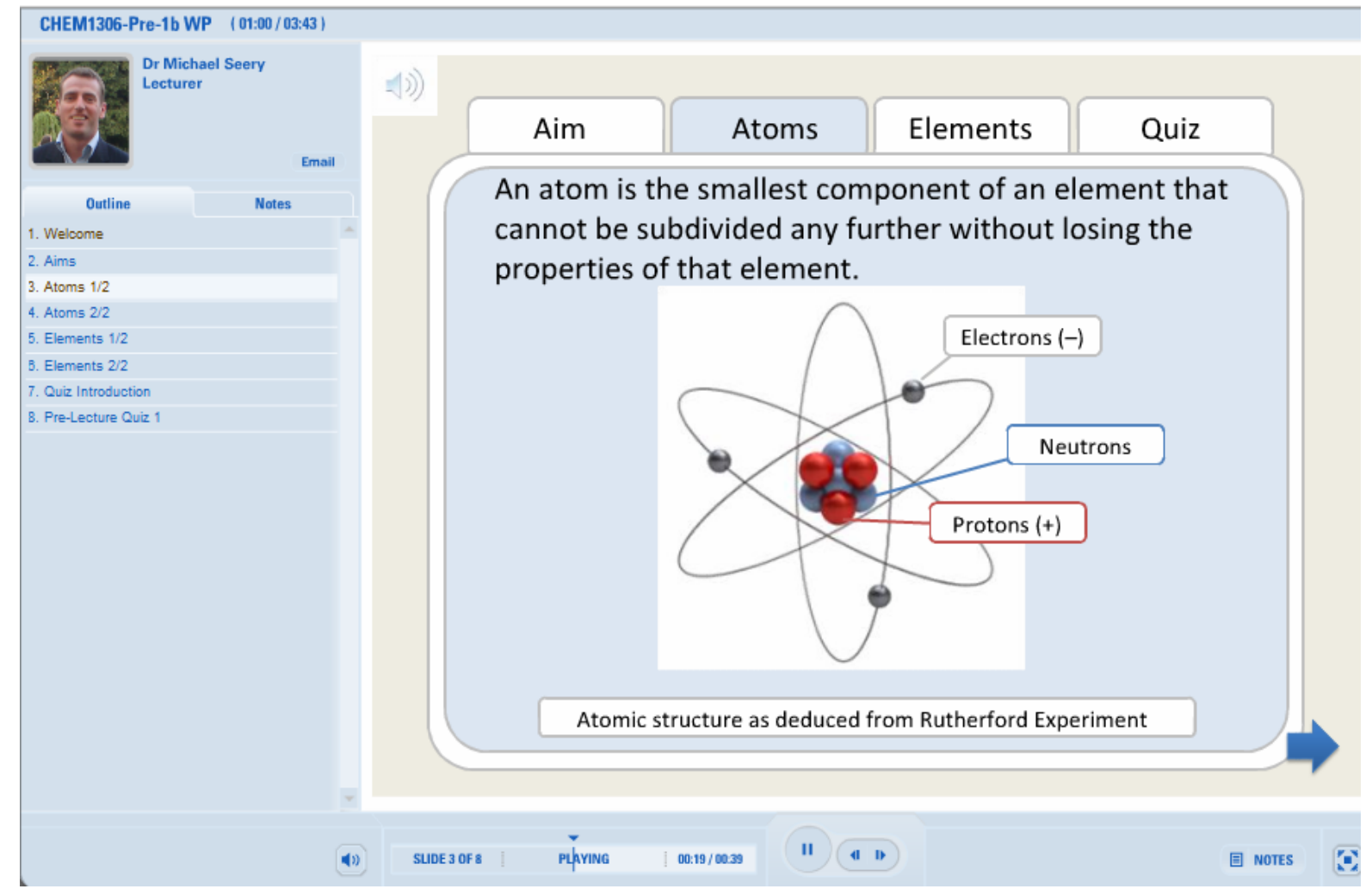

Figure 1: Screenshot of a pre-lecture resource

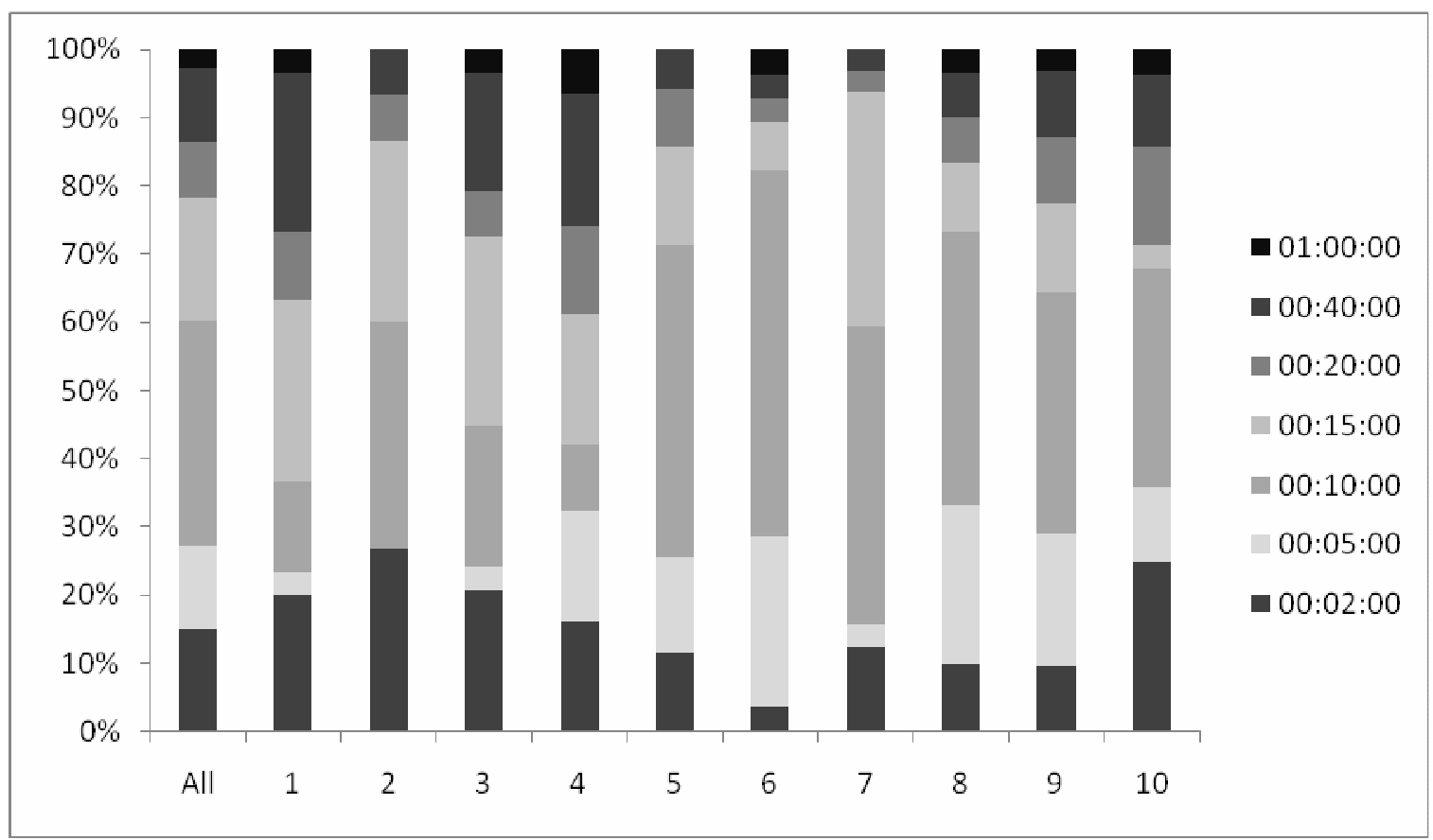

Figure 2: Frequency distribution showing proportion of students by the time spent on resource by time range 


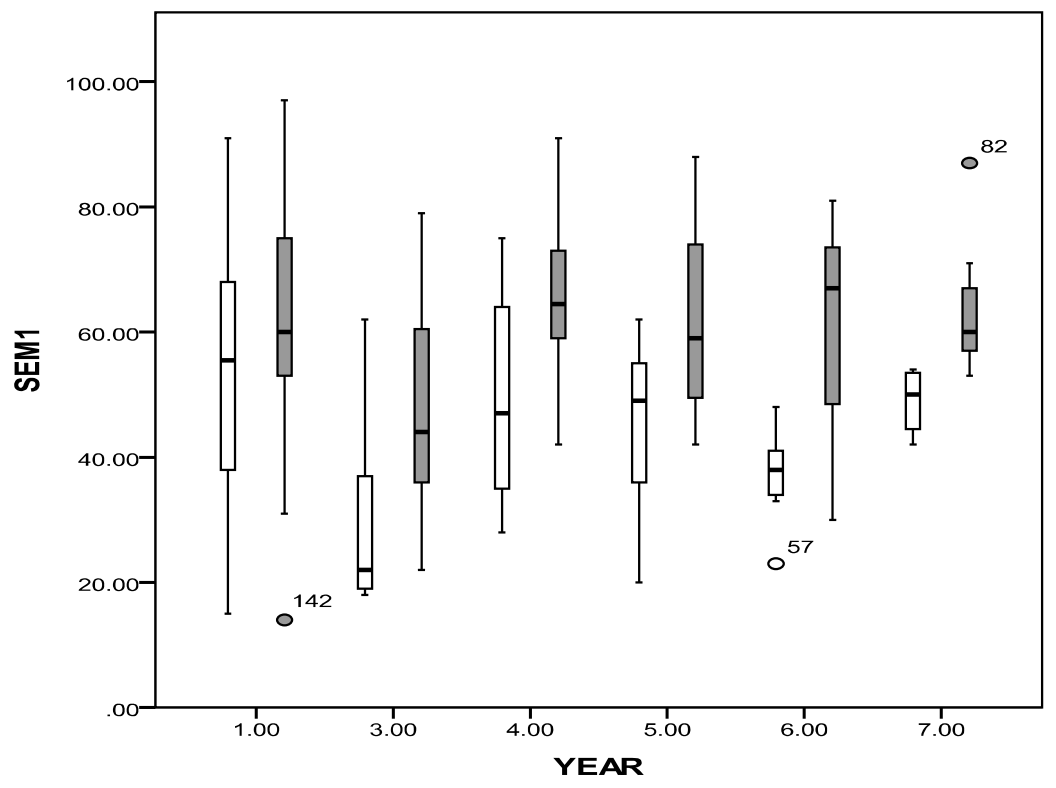

Figure 3: Box-plots showing range of marks obtained by students in their semester test for the current year (Year 1) and several previous years, distinguished by whether they had (filled) or had not (unfilled) prior knowledge of chemistry 
Table 1: Access data for module including SCORM data which details access details on resources for lectures held on Mondays 3-4 pm and Thursdays 11 - 12 pm

\begin{tabular}{|c|c|c|c|c|c|c|}
\hline Resource & $\begin{array}{c}\text { Module } \\
\text { Access } \\
\text { Count }\end{array}$ & $\begin{array}{c}\text { SCORM } \\
\text { Access } \\
\text { Count }\end{array}$ & $\begin{array}{c}\text { Average } \\
\text { SCORM } \\
\text { Time }\end{array}$ & $\begin{array}{c}\text { \% Total } \\
\text { time on } \\
\text { SCORM }\end{array}$ & $\begin{array}{c}\text { Most } \\
\text { Accessed Day }\end{array}$ & $\begin{array}{c}\text { Most } \\
\text { Accessed } \\
\text { Time }\end{array}$ \\
\hline$\# 1$ & 93 & 110 & $06: 39$ & $85 \%$ & Wednesday & $8-9 \mathrm{pm}$ \\
\hline$\# 2$ & 57 & 42 & $05: 13$ & $65 \%$ & Sunday & $9-10 \mathrm{am}$ \\
\hline$\# 3$ & 78 & 72 & $06: 50$ & $84 \%$ & Wednesday & $9-10 \mathrm{pm}$ \\
\hline$\# 4$ & 121 & 103 & $06: 21$ & $69 \%$ & Sunday & $1-2 \mathrm{pm}$ \\
\hline$\# 5$ & 113 & 82 & $05: 52$ & $76 \%$ & Tuesday & $3-4 \mathrm{pm}$ \\
\hline NONE & 81 & 12 & $01: 33$ & $15 \%$ & Thursday & $1-2 \mathrm{pm}$ \\
\hline$\# 6$ & 88 & 70 & $08: 55$ & $80 \%$ & Wednesday & $5-6 \mathrm{pm}$ \\
\hline$\# 7$ & 96 & 81 & $08: 09$ & $70 \%$ & Sunday & $3-4 \mathrm{pm}$ \\
\hline$\# 8$ & 71 & 62 & $09: 41$ & $68 \%$ & Sunday & $1-2 \mathrm{pm}$ \\
\hline$\# 9$ & 71 & 117 & $05: 37$ & $57 \%$ & Wednesday & $7-8 \mathrm{pm}$ \\
\hline$\# 10$ & 79 & 53 & $10: 54$ & $74 \%$ & Sunday & $2-3 \mathrm{pm}$ \\
\hline $\begin{array}{c}\text { Average } \\
\text { (excluding } \\
\text { "NONE") }\end{array}$ & 87 & 80 & $07: 25$ & $73 \%$ & & \\
\hline
\end{tabular}

Table 2: Pearson's r correlation values between the variables CAO score, prior knowledge score, semester and module exam marks. (** indicates value significant at the $p<.01$ level)

\begin{tabular}{|l|r|r|r|}
\hline & \multicolumn{1}{|c|}{ PK } & \multicolumn{1}{c|}{ SEM } & \multicolumn{1}{c|}{ EXAM } \\
\hline CAO & -.020 & .296 & $.526^{* *}$ \\
\hline PK & & .234 & -.094 \\
\hline SEM & & & $.674^{* *}$ \\
\hline
\end{tabular}

